\title{
Seasonal associations of climatic drivers and malaria in the highlands of Ethiopia
}

\author{
Alemayehu Midekisa', Belay Beyene ${ }^{2}$, Abere Mihretie $^{3}$, Estifanos Bayabil $^{3}$ and Michael C. Wimberly ${ }^{1 *}$ (D)
}

\begin{abstract}
Background: The impacts of interannual climate fluctuations on vector-borne diseases, especially malaria, have received considerable attention in the scientific literature. These effects can be significant in semi-arid and highelevation areas such as the highlands of East Africa because cooler temperature and seasonally dry conditions limit malaria transmission. Many previous studies have examined short-term lagged effects of climate on malaria (weeks to months), but fewer have explored the possibility of longer-term seasonal effects.
\end{abstract}

Methods: This study assessed the interannual variability of malaria occurrence from 2001 to 2009 in the Amhara region of Ethiopia. We tested for associations of climate variables summarized during the dry (January-April), early transition (May-June), and wet (July-September) seasons with malaria incidence in the early peak (May-July) and late peak (September-December) epidemic seasons using generalized linear models. Climate variables included land surface temperature (LST), rainfall, actual evapotranspiration (ET), and the enhanced vegetation index (EVI).

Results: We found that both early and late peak malaria incidence had the strongest associations with meteorological conditions in the preceding dry and early transition seasons. Temperature had the strongest influence in the wetter western districts, whereas moisture variables had the strongest influence in the drier eastern districts. We also found a significant correlation between malaria incidence in the early and the subsquent late peak malaria seasons, and the addition of early peak malaria incidence as a predictor substantially improved models of late peak season malaria in both of the study sub-regions.

Conclusions: These findings suggest that climatic effects on malaria prior to the main rainy season can carry over through the rainy season and affect the probability of malaria epidemics during the late malaria peak. The results also emphasize the value of combining environmental monitoring with epidemiological surveillance to develop forecasts of malaria outbreaks, as well as the need for spatially stratified approaches that reflect the differential effects of climatic variations in the different sub-regions.

Keywords: Malaria, Epidemic, Climate, Weather, Early warning, Mosquito

\section{Background}

The impact of interannual climate fluctuations on vector-borne diseases, especially malaria, has received considerable attention in the scientific literature [1-4]. The influences of climatic variations on malaria risk can be especially pronounced in semi-arid and highelevation areas such as the highlands of East Africa $[3,5]$. Cool temperatures and seasonally dry conditions limit malaria transmission in the highlands, and as a result population-level immunity is typically low [6].

\footnotetext{
* Correspondence: michael.wimberly@sdstate.edu

${ }^{1}$ Geospatial Sciences Center of Excellence (GSCE), South Dakota State University, Brookings, SD, USA

Full list of author information is available at the end of the article
}

However, epidemics can still occur in response to abnormally warm temperatures and wet conditions. Multiple large-scale epidemics of malaria have been documented in the East African highlands in recent decades [7-9]. Malaria epidemics in these regions can create a large disease burden with high rates of mortality and morbidity across all age groups. Because of the devastating nature of these epidemics, understanding the effects of short-term climate variations on malaria transmission is an important step toward allowing public health decision makers to plan intervention strategies more effectively.

Although temporal variations in malaria transmission are influenced by multiple factors including land use

\section{Biomed Central}

(c) 2015 Midekisa et al. This is an Open Access article distributed under the terms of the Creative Commons Attribution License (http://creativecommons.org/licenses/by/4.0), which permits unrestricted use, distribution, and reproduction in any medium, provided the original work is properly credited. The Creative Commons Public Domain Dedication waiver (http:// creativecommons.org/publicdomain/zero/1.0/) applies to the data made available in this article, unless otherwise stated. 
change, public health interventions, and other socioeconomic determinants, the role of climate is crucial [10]. For example, an earlier study reported associations of interannual variation in temperature and rainfall with malaria outpatient cases in the East African highlands including Ethiopia, Kenya, and Uganda [3]. Strong associations of temperature and rainfall with malaria cases were also found in the highlands of Ethiopia [11]. Temperature influences the development and survival rates of both the anopheline mosquito vectors and the Plasmodium parasites that cause malaria; as a result, malaria transmission rates tend to increase with temperature up to a threshold level [12, 13]. Higher temperature will increase the feeding frequency of female adult mosquitoes, which can increase the probability of transmitting the malaria parasite to uninfected human hosts [14]. The duration of the sporogonic cycle, in which the parasite develops inside the mosquito, also shortens as temperature increases up to an optimum level $[13,15]$. In addition, the longevity of mosquitoes is sensitive to temperature, and there are threshold temperatures above which mosquito mortality increases and minimum temperatures below which mosquitoes become inactive [14]. Anopheline mosquitoes also need surface water to complete their life cycles. Rainfall influences malaria transmission by supplying water to create aquatic habitats, although excessive rainfall may flush breeding sites and cause mortality of mosquito larvae [16-19].

Most previous studies that examined the link between climate and malaria have reported lagged associations of climate variables such as temperature and rainfall with malaria cases over time periods ranging from weeks to months $[3,6,11,20]$. These associations are based on the assumption that short term lags reflect the time required following a climatic anomaly for mosquitoes to develop to adulthood, acquire and transmit a malarial infection, and for symptoms to arise in the human host [11]. However, mosquito populations, mosquito infection rates, and the resulting risk of malaria in humans may also respond to longer-term cumulative effects of climatic fluctuations on mosquito populations and malaria infection levels across multiple seasons. Although malaria transmission during the wet season can be limited by the cooler temperatures associated with summer rains, there is also a potential for carryovers of parasites in the human population to the subsequent epidemic season. Long-term asymptomatic carriage of Plasmodium parasites, especially in regions of seasonal transmission, is common [21-23]. Therefore, there is a possibility that lagged effects of climate variables will extend across multiple seasons. For example, a study in the highlands of western Kenya found evidence of a "ripple effect" in which November-January rainfall was correlated with the number of February-April malaria cases, which was in turn correlated with the number of cases during the main malaria season in May-December [1].

Here, we test this conceptual model in the highlands of the Amhara region of Ethiopia by assessing the effects of satellite-derived climate variables summarized during the dry (January-April), early transition (May-June), and wet (July-September) seasons with malaria incidence in the early (May-July) and late (SeptemberDecember) peak transmission seasons. Districts in western Amhara experience longer and heavier rainy seasons and higher intra-annual variability in temperature, whereas districts in eastern Amhara experience shorter rainy seasons and less intra-annual variability in temperature. Because different factors may influence malaria incidence under each of these climate regimes [9], we analyzed each sub-region separately. We hypothesized that malaria occurrence during the early peak season would be associated with the cumulative effects of climatic conditions during the preceding dry and early transition seasons. We further hypothesized that malaria cases during the early peak season would be correlated with malaria cases during the subsequent late peak season, reflecting the carryover of parasites in the human population. Because of this linkage, and because cooler temperatures during the wet season will likely reduce malaria transmission, malaria during the late peak season should have stronger associations with dry and early transition season climatic variables than wet season climatic variables. We also hypothesized that including early peak malaria incidence as an independent variable in models of late peak season malaria would improve their fit compared to models based on climatic variables alone. Finally, we hypothesized that temperature would be a more important predictor of malaria incidence in the cooler and wetter western districts, whereas moisture would be more important in the warmer and drier eastern districts. We addressed these hypotheses by using remote sensing products derived from multiple earth observation satellites and analyzing the seasonal associations of malaria incidence with climate conditions.

\section{Methods}

\section{Study area}

The study area, the Amhara region, is located in the northwestern and north central parts of Ethiopia and lies within $9^{\circ}$ and $13{ }^{\circ} 45 \mathrm{~N}$ and $36^{\circ}$ and $40^{\circ} 30 \mathrm{E}$ (Fig. 1). The Amhara region has 11 administrative zones and has a total area of approximately $170,000 \mathrm{~km}^{2}$. Elevation ranges from 506 to $4517 \mathrm{~m}$ above sea level. Mean annual rainfall ranges from 770 to $2000 \mathrm{~mm}$ while average annual air temperature ranges from $16{ }^{\circ} \mathrm{C}$ in the summer to $27^{\circ} \mathrm{C}$ in the dry season. In this highland region, malaria is characterized by unstable transmission, and 
outbreaks of malaria can cause high morbidity and mortality because the human population lacks immunity to the pathogen $[24,25]$. For example, the most recent regional malaria epidemics occurred from 2003 to 2005 $[25,26]$. Since that time, malaria outbreaks have generally been smaller and more localized [9]. Anopheles arabiensis is the principal malaria vector in the Amhara region [27], and Plasmodium falciparum and Plasmodium vivax are the major malaria parasites in the region [28]. Ethiopia has a national malaria control program, including the Amhara region, which consists of the distribution of free long-lasting insecticidal nets (LLINs), targeted indoor residual spraying (IRS), rapid diagnostic tests (RDTs), and treatment with artemisinin combination therapy [28]. Malaria transmission is seasonal in the Amhara region following seasonal patterns of climatic factors; the two main

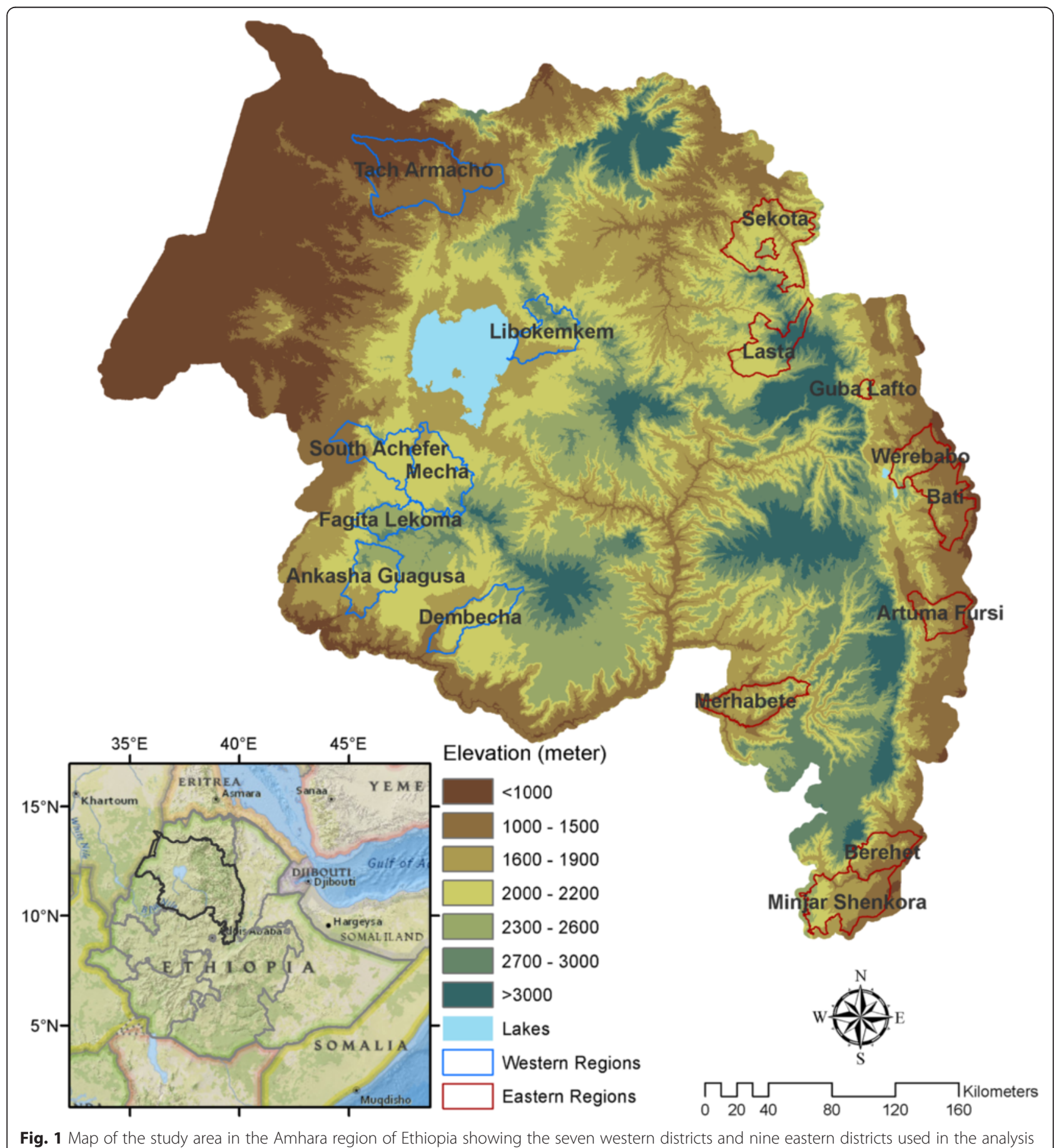


malaria transmission seasons occur in May-July following the end of the dry season and in September-December following the end of the wet season. Previous studies have documented regional spatial synchrony of malaria outbreaks [9], and others have found lagged associations of climate variables and malaria in the region with time lags ranging from 1 to 3 months [20,29].

\section{Environmental data}

We used rainfall estimates from the Tropical Rainfall Measuring Misssion (TRMM) with a spatial resolution of $0.25^{\circ} \times 0.25^{\circ}$. The TRMM preciptation (3B42) product was used to compute seasonal total rainfall $(\mathrm{mm})$ for each district. We used the 8-day land surface temperature (LST) product (MOD11A2) from the Moderate Resolution Imaging Spectroradiometer (MODIS) insrtument, on the Terra satellite, at a $1 \mathrm{~km}$ spatial resolution to calculate seasonal mean LST for each district. We also computed the 8-day enhanced vegetation index (EVI) using surface reflectance in the blue, red and nearinfrared bands from the MODIS Nadir BRDF-Adjusted Reflectance (NBAR) product (MCD43B4) at a $1 \mathrm{~km}$ spatial resolution. All these remote sensing data were processed using the EASTWeb software developed at the Geospatial Sciences Center of Excellence, South Dakota State University [30]. In addition, we obtained satellite-derived 8-day actual evapotranspiration (ET) based on Simplified Surface Energy Balance Operational (SSEBop) model [31]. The SSEBop is an operational ET product that uses MODIS and Global Data Assimilation System (GDAS) data and is available through the U.S. Geological Survey. We summarized these satellitederived climate variables for each district using the zonal statistics method over the 2001-2009 periods. We then calculated seasonal summaries for the dry (day of year (DOY) 1-120), early transition (DOY 121-180), and wet (DOY 181-273) seasons. We computed seasonal means for LST and EVI and seasonal totals for ET and rainfall for each of the three seasons. We also included the districtlevel percent of herbaceous wetlands, which serve as a natural reservoir for the malaria vector, in each district as an independent variable in all the models. Wetland cover was computed from a land cover map for the Amhara region derived from spectral and topographic indices from Landsat TM/ETM+ and the Shuttle Radar Topography Mission (SRTM) respectively [32].

\section{Malaria surveillance data}

We used clinically-diagnosed outpatient malaria cases from 16 districts in the Amhara region. Counts of malaria cases including all age groups and all Plasmodium species for 2001-2009 were collected from multiple district (woreda) health offices and the Federal Ministry of Health, Public Health Emergency Management office by the Health, Development and Anti-Malaria Association, an Ethiopian NGO [9]. Data were reported using the integrated disease surveillance and response (IDSR) summary forms that are routinely used for surveillance of malaria and other infectious diseases [33]. Malaria incidence was calculated by dividing the total number of clinically-diagnosed outpatient malaria cases by the total population of each district based on the 2007 national population census of Ethiopia [34] and multiplying by 1000 to provide malaria incidence per 1000 persons. Malaria incidence over 2001-2009 was calculated for the two main malaria transmission seasons: early peak (May-July) and late peak (September-December). Interannual variability in early and late peak malaria incidence for each district in Fig. 2. We selected the 16 districts for analysis based on availability of the malaria surveillance data for the entire 2001-2009 study period. We divided these districts into western districts (seven districts) and eastern districts (nine districts) based on observed climatological patterns (Figs. 1, 3a and 4a).

\section{Statistical methods}

We conducted exploratory analysis to visualize the seasonal patterns of rainfall and LST in relation to malaria incidence in order to highlight differences in climatology and malaria epidemiology between the two regions. We used a negative binomial generalized linear model (GLM) to test the seasonal associations of malaria incidence and climatic drivers. Separate models were developed for the western and eastern districts. Early peak and late peak season malaria incidence were used as response variables, the natural logarithm of total population was used to account for spatial variability in population, and seasonal climatic variables were used as independent variables. In all the models, we also included percent wetlands as an independent variable to control for the effect of spatial variability in local hydrology [32]. We used a square-root transformation of the percent wetlands to minimize the influences of outlying values and meet the statistical assumptions of the GLM model.

We used a multimodel inference approach to determine the best models for dry, early transition and wet season climate effects on early and late peak malaria. For parsimony, we considered seven candidate models that included all possible combinations of the temperature variable (LST), and one of the three moisture indicators (rainfall, ET, and EVI) (Tables 1 and 2). The models were assessed using Akaike Information Criterion (AIC) scores, which measure the relative goodness of model fit. Additionally, we used Akaike weights to evaluate these models [35]. Akaike weights measure the probability that a model is the best model given the data and the 


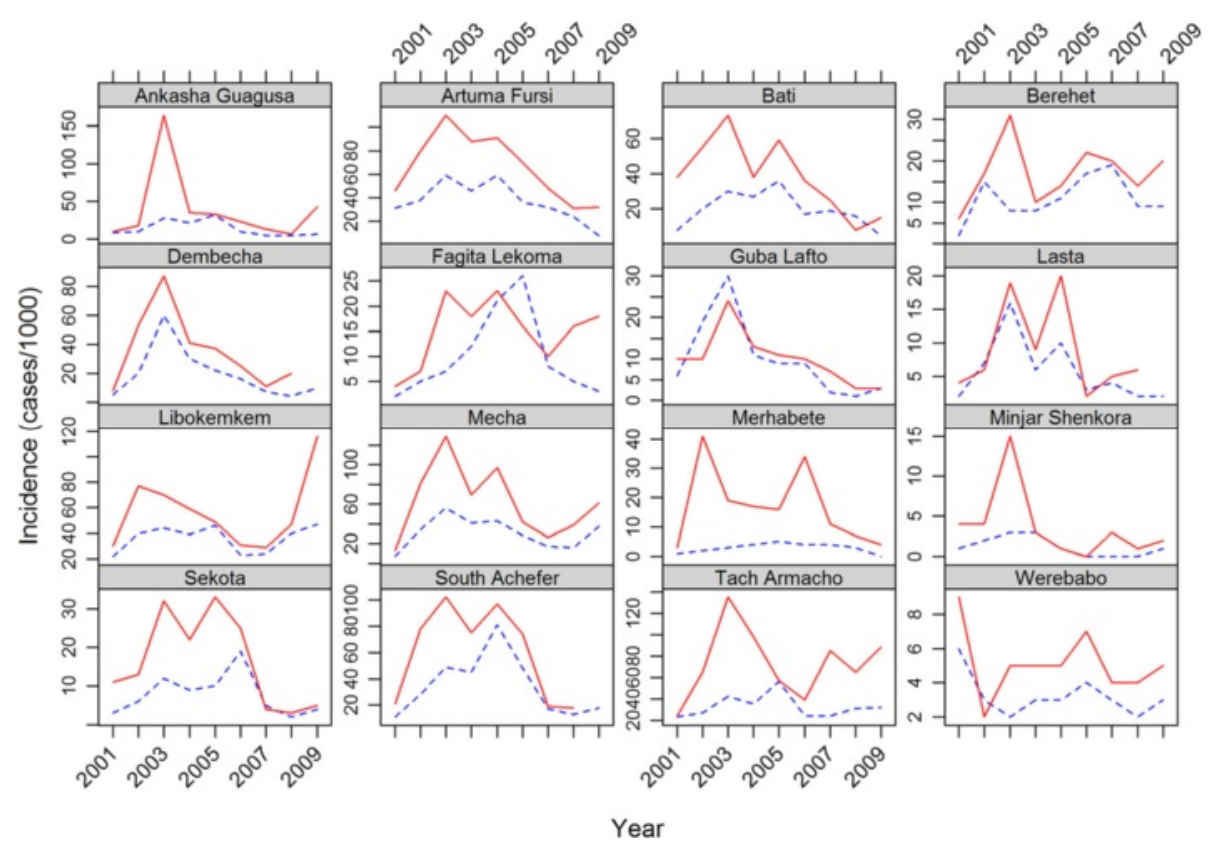

Fig. 2 Interannual variability in early peak (blue dashed lines) and late peak (red solid lines) malaria incidence from 2001 to 2009 for 16 districts in the Amhara region. Locations of the 16 districts are referenced in Fig. 1

set of candidate models [35]. Lower AIC statistics and higher Akaike weights indicated better model fit.

We used Spearman's rank correlation to test the association between early and late peak season malaria incidence. The correlation analysis was based on malaria incidence in each of the two sub regions for 2001-2009. We calculated malaria incidence rates by summing the annual numbers of early and late peak malaria cases over the districts in each sub region and dividing by the total population summed over the districts in each sub region. A separate Spearman's rank correlation was also computed for each of the 16 sub-districts. We tested whether including early peak malaria incidence as an independent variable improved the fit of the best climatic models of late peak malaria by comparing model 1 (with early peak malaria incidence as an independent variable) with model 2 (without early peak malaria incidence as an independent variable) using AIC as described previously. We conducted all statistical modeling in the $\mathrm{R}$ environment for statistical computing [36].

\section{Results}

The two sub-regions of the Amhara region showed different climatic conditions. The eastern districts had shorter summer rains and less intra-annual variation in temperature, whereas the western districts had longer summer rains and higher intra-annual variation in temperature (Figs. 3a and 4a). Moreover, the eastern districts experienced an earlier, smaller peak of rainfall from March-May. Overall, the western districts were characterized by wetter and colder climates while the eastern districts had drier and warmer climates. The malaria incidence data showed two distinct peaks during the early and late peak malaria transmission periods (Figs. 3b and 4b); the former matched with the start of the wet season (summer rains) while the latter followed the end of the wet season. In the eastern districts the early peak malaria season began sooner than in the western districts. The western districts had a higher malaria incidence overall.

Table 1 summarizes the AIC scores and weights for the seven models for early peak malaria in the two subregions based on climatic variables from the dry and early transition seasons. In the dry season models, LST had a strong influence and adding moisture variables did not substantially improve model fit in the western districts, whereas moisture variables had the strongest influence and adding LST did not improve model fit in the eastern districts. In the early transition season models, LST had the strongest influence and adding moisture variables did not improve model fit in the western districts, whereas both LST and moisture indicators contributed to the fit of the best model in the eastern districts. Overall, for the models of early peak season malaria, LST had the strongest influence in the western districts, whereas moisture variables were more important in the eastern districts (Table 1). There was no substantive difference (delta AIC values <2) between the best models based on dry season climate and early transition season climate in either region. 

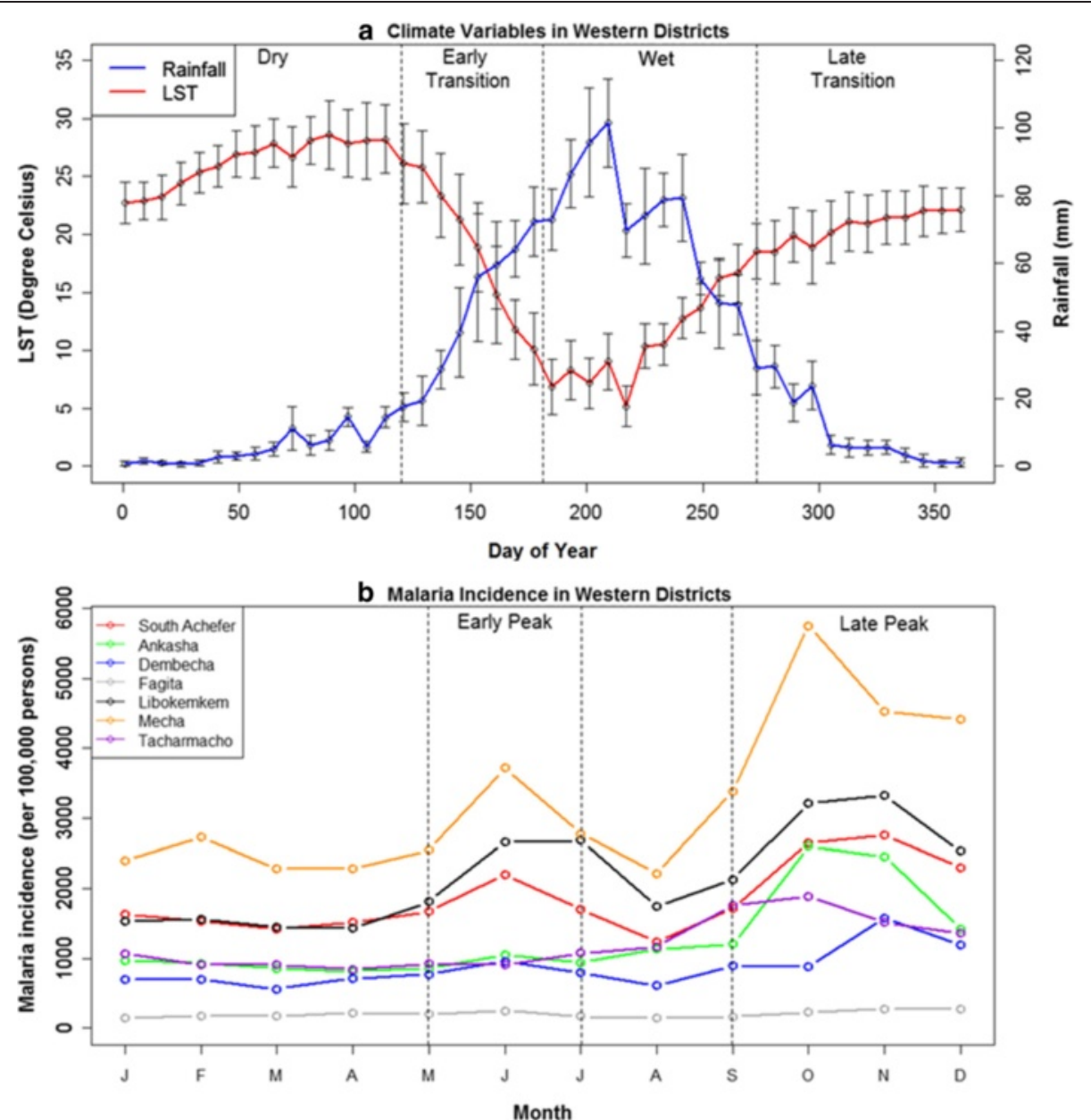

Fig. 3 a Seasonal patterns of satellite-derived estimates of rainfall and land surface temperature (LST) averaged over the 2001-2009 period for the seven western districts in the Amhara region, Ethiopia. b Seasonal pattern of malaria incidence (per 100,000) in the seven western districts. The vertical bars represent one standard deviation and show variability among districts. The seven western districts are referenced in Fig. 1

Table 2 summarizes the seven models for late peak season malaria in the two sub-regions based on climatic variables from the dry, early transition, and wet seasons. In the dry and early transition season models, LST had the strongest influence in the western districts and adding moisture variables did not substantially improve model fit, whereas both LST and moisture contributed to model fit in the eastern districts. In the wet season models, moisture variables had the strongest influence and adding LST did not substantially improve model fit in the western districts, whereas both LST and moisture variables contributed to model fit in the eastern districts. Overall, the most parsimonious models of late peak season malaria in the western districts were driven by LST alone in the dry and early transition season models and by rainfall alone in the wet season model. In contrast, the best models of late peak season malaria in the eastern districts included a combination of LST and moisture variables in all three seasons (Table 2). In the western districts, the best model based on early transition season climate had a better fit than the best models based on dry and wet season climate as indicated by its lowest AIC value. In the eastern districts, the best models based on dry and early transition season climate both had better fits than the best model based on wet season climate. There was no substantive difference (delta AIC values $<2$ ) between the best models based on dry season climate versus early transition season climate in the eastern districts.

Early peak malaria incidence was strongly associated with the subsequent late peak malaria incidence. Spearman's rank correlation of early and late peak malaria incidence was 0.97 ( $p$-value $<0.001)$ for the western districts combined and 0.91 ( $p$-value $<0.001$ ) for the eastern districts combined. Spearman rank correlations of early and late peak malaria incidence in the individual districts were all positive and were statistically significant (alpha-level of 0.05) in 12 of the 16 districts (Table 3). 

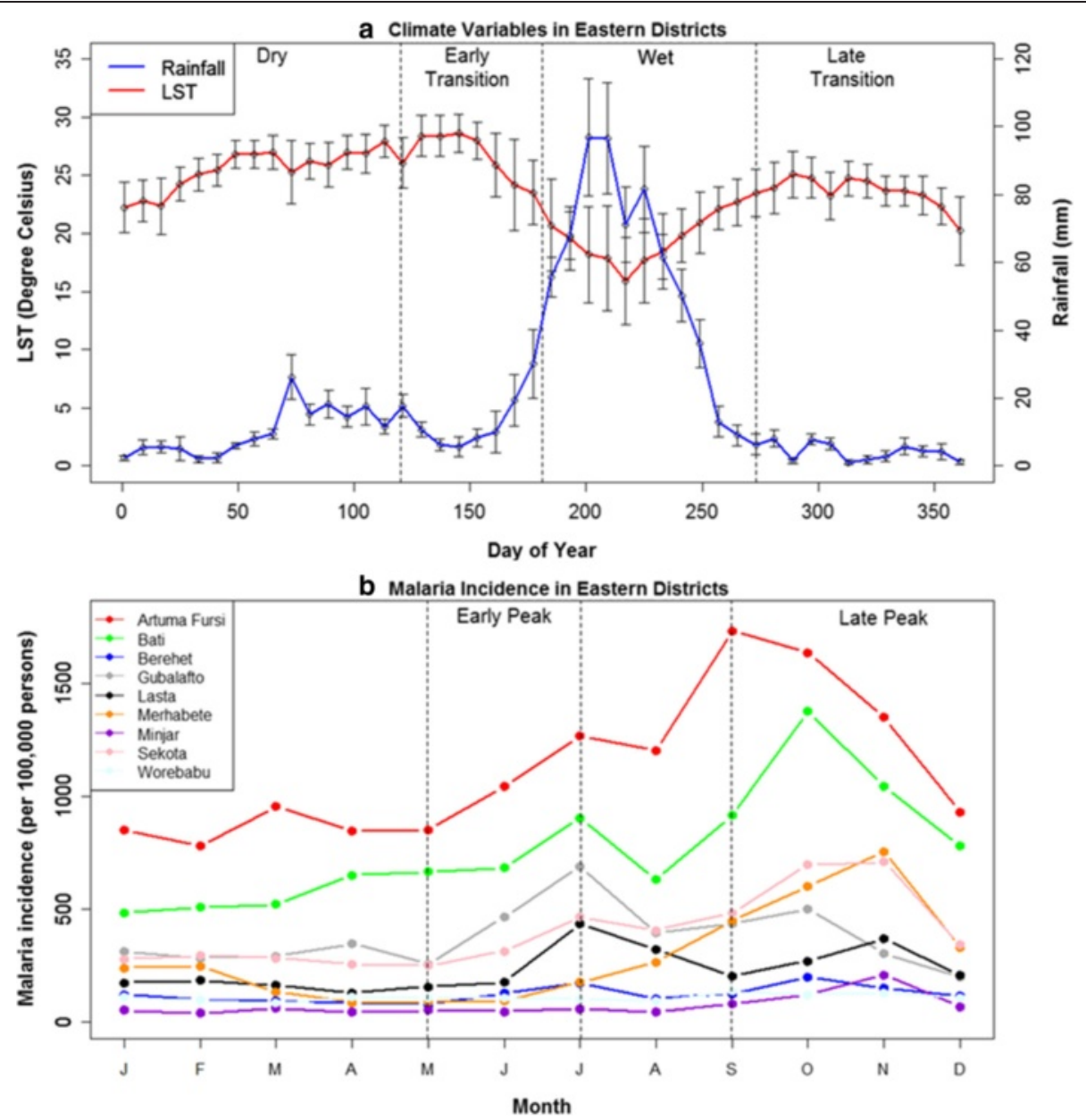

Fig. 4 a Seasonal pattern of satellite-derived estimates of rainfall and land surface temperature (LST) averaged over the 2001-2009 periods for the nine eastern districts. b Seasonal pattern of malaria incidence (per 100,000) in the nine eastern districts. The vertical bars represent one standard deviation and show variability among districts. The nine eastern districts are referenced in Fig. 1

For late peak season malaria, we compared two GLM models including model 1 (without early peak malaria) and model 2 (with early peak malaria) based on the best model for each season in order to evaluate the influence of early peak malaria incidence on subsequent late peak season epidemics (Table 4). In the western districts, model 2 was the best model as compared to model 1 across all the seasons including the dry (Akaike weight $=1.0$ ), early transition (Akaike weight $=0.99$ ) and wet (Akaike weight $=1.0$ ) seasons. Similarly, in the eastern districts, model 2 was the best model as compared to model 1 across the dry (Akaike weight $=1.0$ ), early transition (Akaike weight $=1.0$ ) and wet (Akaike weight = 1.0) seasons. Additionally, model comparison based on root mean square error (RMSE) showed that model 2 was the best model in all the three seasons across the two regions (Fig. 5). Overall, our results showed that the addition of early peak malaria incidence as an independent variable in model 2 substantially improved model fit in the dry, early transition and wet season models for both regions.

\section{Discussion}

In the Amhara region of Ethiopia, early peak malaria was associated with climate conditions during the preceding dry, and early transition seasons. Moreover, early peak malaria incidence was correlated with malaria incidence during the subsequent late peak season, and malaria incidence during the late peak season had stronger associations with dry, and early transition climate conditions than wet season climate conditions. These results supported a conceptual model of cascading seasonal effects in which the influences of climate on mosquito population dynamics and parasite development are high at the end of the dry season and the beginning of the wet season, and the resulting effects on human disease are then sustained through the wet season and influence malaria incidence during the subsequent late peak 
Table 1 Early peak season malaria model results in the western and eastern districts

\begin{tabular}{|c|c|c|c|c|c|c|c|}
\hline \multirow[b]{2}{*}{ Season } & \multirow[b]{2}{*}{ Model rank } & \multicolumn{3}{|c|}{ Western districts } & \multicolumn{3}{|c|}{ Eastern districts } \\
\hline & & Variables & AIC & Akaike weight & Variables & $\mathrm{AlC}$ & Akaike weight \\
\hline \multirow[t]{7}{*}{ Dry } & 1 & LST, ET & 508.6 & 0.44 & ET & 552.8 & 0.58 \\
\hline & 2 & LST, EVI & 509.7 & 0.26 & LST, ET & 553.6 & 0.39 \\
\hline & 3 & LST & 510.2 & 0.20 & LST, EVI & 559.0 & 0.03 \\
\hline & 4 & LST, Rainfall & 512.1 & 0.08 & $\mathrm{EVI}$ & 560.9 & 0.01 \\
\hline & 5 & $\mathrm{EVI}$ & 514.6 & 0.02 & LST, Rainfall & 575.3 & 0.00 \\
\hline & 6 & ET & 517.7 & 0.00 & Rainfall & 577.3 & 0.00 \\
\hline & 7 & Rainfall & 521.0 & 0.00 & LST & 577.9 & 0.00 \\
\hline \multirow[t]{7}{*}{ Early } & 1 & LST & 509.5 & 0.43 & LST, ET & 553.0 & 0.85 \\
\hline & 2 & LST, Rainfall & 510.9 & 0.22 & ET & 557.5 & 0.09 \\
\hline & 3 & LST, ET & 511.4 & 0.17 & LST, EVI & 558.4 & 0.06 \\
\hline & 4 & LST, EVI & 511.5 & 0.16 & $\mathrm{EVI}$ & 565.3 & 0.00 \\
\hline & 5 & $\mathrm{EVI}$ & 516.3 & 0.01 & LST & 573.5 & 0.00 \\
\hline & 6 & ET & 518.4 & 0.01 & LST, Rainfall & 574.5 & 0.00 \\
\hline & 7 & Rainfall & 521.1 & 0.00 & Rainfall & 578.1 & 0.00 \\
\hline
\end{tabular}

LST land surface temperature, EVI enhanced vegetation index, ET actual evapotranspiration

Table $\mathbf{2}$ Late peak season malaria model results in the western and eastern districts

\begin{tabular}{|c|c|c|c|c|c|c|c|}
\hline \multirow[b]{2}{*}{ Season } & \multirow[b]{2}{*}{ Model rank } & \multicolumn{3}{|c|}{ Western districts } & \multicolumn{3}{|c|}{ Eastern districts } \\
\hline & & Variables & $\mathrm{AlC}$ & Akaike weight & Variables & $\mathrm{AlC}$ & Akaike weight \\
\hline \multirow[t]{7}{*}{ Dry } & 1 & LST & 568.1 & 0.34 & LST, EVI & 634.0 & 0.64 \\
\hline & 2 & LST, ET & 568.5 & 0.28 & LST, ET & 635.2 & 0.35 \\
\hline & 3 & LST, EVI & 569.2 & 0.19 & ET & 644.2 & 0.00 \\
\hline & 4 & LST, Rainfall & 569.6 & 0.16 & $\mathrm{EVI}$ & 648.2 & 0.00 \\
\hline & 5 & $\mathrm{EVI}$ & 574.2 & 0.02 & LST, Rainfall & 649.5 & 0.00 \\
\hline & 6 & Rainfall & 575.0 & 0.01 & LST & 656.3 & 0.00 \\
\hline & 7 & ET & 576.5 & 0.01 & Rainfall & 662.0 & 0.00 \\
\hline \multirow[t]{7}{*}{ Early } & 1 & LST & 554.7 & 0.38 & LST, EVI & 635.9 & 0.66 \\
\hline & 2 & LST, ET & 555.0 & 0.33 & LST, ET & 637.2 & 0.34 \\
\hline & 3 & LST, Rainfall & 556.5 & 0.15 & LST & 649.2 & 0.00 \\
\hline & 4 & LST, EVI & 556.7 & 0.14 & LST, Rainfall & 650.8 & 0.00 \\
\hline & 5 & ET & 564.1 & 0.00 & ET & 653.7 & 0.00 \\
\hline & 6 & $\mathrm{EVI}$ & 569.0 & 0.00 & $\mathrm{EVI}$ & 654.2 & 0.00 \\
\hline & 7 & Rainfall & 576.3 & 0.00 & Rainfall & 663.4 & 0.00 \\
\hline \multirow[t]{7}{*}{ Wet } & 1 & Rainfall & 572.1 & 0.56 & LST, ET & 639.0 & 0.79 \\
\hline & 2 & LST, Rainfall & 573.6 & 0.26 & LST, EVI & 642.4 & 0.14 \\
\hline & 3 & ET & 576.2 & 0.07 & LST, Rainfall & 645.1 & 0.04 \\
\hline & 4 & $\mathrm{EVI}$ & 577.1 & 0.05 & LST & 645.9 & 0.03 \\
\hline & 5 & LST, ET & 578.1 & 0.03 & ET & 656.5 & 0.00 \\
\hline & 6 & LST, EVI & 579.1 & 0.02 & $\mathrm{EVI}$ & 660.0 & 0.00 \\
\hline & 7 & LST & 579.3 & 0.02 & Rainfall & 664.4 & 0.00 \\
\hline
\end{tabular}


Table 3 Summary of Spearman rank correlation coefficients between early and late peak malaria incidence for the western and eastern districts

\begin{tabular}{llc}
\hline Sub region & District & Correlation \\
\hline Eastern districts & Artuma Fursi & $0.97^{* *}$ \\
& Bati & $0.78^{* *}$ \\
Berehet & 0.46 \\
Guba Lafto & $0.85^{* *}$ \\
Lasta & $0.76^{*}$ \\
Merhabete & 0.37 \\
Minjar Shenkora & $0.68^{*}$ \\
Sekota & $0.87^{*}$ \\
Western districts & $0.62^{*}$ \\
& South Achefer & $0.81^{* *}$ \\
Ankasha Guangusa & $0.63^{*}$ \\
Dembecha & $0.86^{* *}$ \\
& Fagita Lekoma & 0.44 \\
& Libokemkem & $0.77^{*}$ \\
Mecha & $0.93^{* *}$ \\
Tach Armacho & 0.56 \\
\hline
\end{tabular}

${ }^{*} 0.01<=p<0.05$

${ }^{* *} p<0.01$

season. Further, our results showed that temperature (LST) was the main climatic driver of malaria incidence in the western districts while moisture variables (rainfall, EVI, ET) were important drivers in the eastern districts.

A study in Botswana similarly reported the association of seasonal rainfall (December-February) with malaria incidence during the peak malaria transmission periods (March-April) [37]. The results of our study further suggest that temperature, as well as precipitation, may be an important constraint on malaria at the beginning of the rainy season in highland areas such as the Amhara region. We would expect carryover of malaria transmission from the early to late peak seasons because of long-term asymptomatic carriage of Plasmodium parasites in the human population [21-23]. These findings are consistent with earlier work in the western highlands of Kenya that reported strong influences of precipitation on early malaria cases prior to the rainy season, and

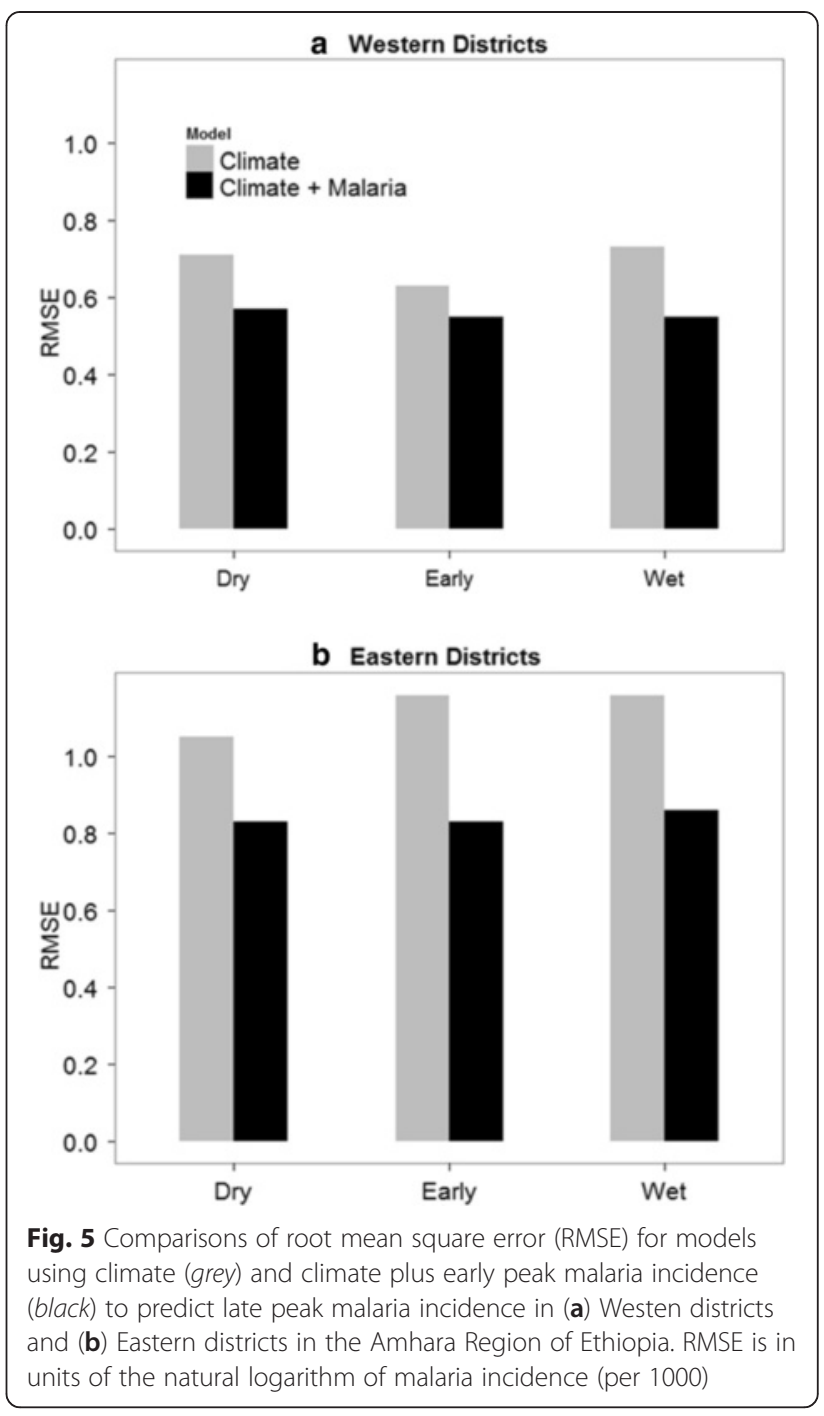

subsequent association of early peak cases with late peak cases after the rainy season [1]. Our results from the Ethiopian highlands suggest that this type of "ripple effect" may be a more generalized phenomenon of malaria epidemiology in regions characterized by seasonal climates.

Because of these carryover effects, the addition of early peak malaria incidence as an independent variable in

Table 4 Best-fitting models predicting late peak season malaria in western and eastern districts

\begin{tabular}{llccccc}
\hline & Season & Model 1 AIC & Model 2 AIC & Delta AIC & Akaike weight model 1 & Akaike weight model 2 \\
\hline Western districts & Dry & 568.11 & 549.09 & 19.02 & 0.00 & 1.00 \\
& Early & 554.75 & 543.27 & 11.48 & 0.003 & 0.99 \\
& Wet & 572.13 & 544.18 & 27.95 & 0.00 & 1.00 \\
\multirow{5}{*}{ Eastern districts } & Dry & 633.98 & 593.61 & 40.37 & 0.00 & 1.00 \\
& Early & 635.95 & 592.90 & 43.05 & 0.00 & 1.00 \\
& Wet & 638.99 & 600.78 & 38.21 & 0.00 & 1.00 \\
\hline
\end{tabular}

model 1 (without early peak malaria incidence), model 2 (with early peak malaria incidence) 
models of late peak season malaria improved fit compared with models that used climate variables alone. The association between early and late peak malaria was consistent across models using dry, early transition and wet season climatic factors in both sub-regions. Previous studies also confirmed that the addition of monthly lagged malaria cases to time series models improves prediction of malaria $[20,29]$; however, our analysis used malaria data summarized over multiple seasons rather than weekly or monthly time series. This finding emphasizes the importance of accounting for both preceding climate condition and recent trends in malaria indicators in modeling and forecasting efforts. Earlier work has also highlighted the need for integrating early detection (based on disease surveilance) and early warning (based on environmental monitoring) approaches to enhance control and elimination strategies for malaria $[20,30,38,39]$.

In the colder western districts, temperature may limit the growth and biting rates of anopheline mosquitoes and increase the duration of sporogonic cycles of the Plasmodium parasites. In contrast, in the drier eastern districts, soil moisture can limit availability of potential breeding sites and thereby limit the development of anopheline larvae and decrease mosquito abundance. These underlying relationships are reflected in the subregional models, in which moisture variables had a stronger relative importance in the eastern districts than in the western districts. These results were also consistent with a previous study in Ethiopia that reported minimum temperature was significantly associated with malaria cases in the cold districts, whereas rainfall was associated with transmission in the hot districts [11]. More generally, multiple studies across Africa and the globe have found that the relative importance of climatic drivers varies geographically depending on the local climate setting, land cover and land use, and hydrology [3, 40, 41]. Thus, our findings support the importance of spatial stratification and the development of forecasting approaches that incorporate spatial heterogeneity in the underlying relationships with climate [40].

Findings from the current study emphasize the importance of understanding both the spatially heterogenous effects of preceding seasonal climatic factors on malaria as well as the potential for carryover of malaria throughout the transmission periods. However, our study has several limitations which may have influenced the results of our analysis. District-level intervention data such as longlasting insecticide-treated nets, and indoor residual spraying were not available and were not incorporated in our models. As a result of a large scale national control strategy by the government of Ethiopia, approximately 20 million long-lasting insecticide-treated nets (LLINs) have been distributed to all malarious areas all over the country including the Amhara region. Further, the analysis examined associations of climate variables and malaria incidence at the relatively coarse spatial scale of districts ranging from approximately 80 to $2700 \mathrm{~km}^{2}$ in size. Yet we expect that there are also more localized ecological and land cover determinants may also influence transmission, and these relationships could be better represented at a finer sub-district scale analysis. We suggest that future studies build on these findings and further assess the associations of seasonal climate variation and malaria by including public health interventions, socioeconomic factors, irrigation and population mobility data at finer spatial scales, including kebele (sub-district administrative unit) and village levels.

\section{Conclusions}

Our study found strong associations of malaria incidence in the early and late peak transmission seasons with preceding climate conditions in the dry, and early transition seasons. Temperature had the strongest influence on malaria incidence in the western districts, whereas moisture variables were more important in the eastern districts. Additionally, our results confirmed strong correlations between malaria incidence in the early and subsequent late peak transmission seasons, and the addition of early peak malaria incidence as an independent variablestrongly improved the fit of the late peak season malaria models. Overall, our findings suggest that associations between the preceding seasonal climate conditions and subsequent malaria transmission during the late peak season may be due to the cumulative effects of climatic factors as well as the potential for parasite carriage across multiple seasons. As a result, forecasting model predictions could be improved by incorporating both preceding climate condition and malaria incidence, which suggests the importance of combining early detection and early warning approaches for malaria epidemic forecasting [42]. Additionally, the finding of different climatic effects on malaria in the different sub-regions emphasizes the the need for spatial stratification and the development of localized models for malaria forecasting.

\section{Competing interests}

The authors declare that they have no competing interests.

\section{Authors' contributions}

$\mathrm{AM}$ and MCW designed the study, processed the remote sensing data, analyzed the data, and drafted the manuscript. BB, AM, and EB selected the study areas and developed the epidemiological database. All authors read and approved the final manuscript.

\section{Acknowledgments}

We acknowledge the Amhara National Regional State Health Bureau for their cooperation. We thank Paulos Semuniguse and Hiwot Teka for their efforts in collecting the malaria surveillance data. We also thank Christopher Merkord for reviewing an earlier version of this manuscript. This work was funded by NASA through the NASA Earth and Space Science Fellowship (NESSF) program (grant number NNX11AP79H), and by the National Institute of Allergy and Infectious Diseases (grant number R01Al079411). 


\section{Author details}

${ }^{1}$ Geospatial Sciences Center of Excellence (GSCE), South Dakota State University, Brookings, SD, USA. ${ }^{2}$ Amhara Regional Health Bureau, Bahir Dar, Ethiopia. ${ }^{3}$ Health Development and Anti-Malaria Association, Addis Ababa, Ethiopia.

Received: 28 November 2014 Accepted: 13 June 2015

Published online: 24 June 2015

\section{References}

1. Pascual M, Cazelles B, Bouma MJ, Chaves LF, Koelle K. Shifting patterns: malaria dynamics and rainfall variability in an African highland. Proc Biol Sci. 2008:275(1631):123-32

2. Patz JA, Olson SH. Malaria risk and temperature: influences from global climate change and local land use practices. Proc Natl Acad Sci U S A. 2006;103(15):5635-6.

3. Zhou G, Minakawa N, Githeko AK, Yan GY. Association between climate variability and malaria epidemics in the East African highlands. Proc Nat Acad Sci U S A. 2004;101(8):2375-80.

4. Pascual M, Ahumada JA, Chaves LF, Rodo X, Bouma M. Malaria resurgence in the East African highlands: temperature trends revisited. Proc Natl Acad Sci U S A. 2006;103(15):5829-34.

5. Alonso D, Bouma MJ, Pascual M. Epidemic malaria and warmer temperatures in recent decades in an East African highland. Proc Biol Sci. 2011;278(1712):1661-9

6. Abeku TA, de Vlas SJ, Borsboom G, Teklehaimanot A, Kebede A, Olana D, et al. Forecasting malaria incidence from historical morbidity patterns in epidemic-prone areas of Ethiopia: a simple seasonal adjustment method performs best. Trop Med Int Health. 2002;7(10):851-7.

7. Hay SI, Cox J, Rogers DJ, Randolph SE, Stern DI, Shanks GD, et al. Climate change and the resurgence of malaria in the East African highlands. Nature. 2002;415(6874):905-9.

8. Lindsay SW, Martens WJM. Malaria in the African highlands: past, present and future. Bull World Health Organ. 1998;76(1):33-45.

9. Wimberly MC, Midekisa A, Semuniguse P, Teka H, Henebry GM, Chuang TW, et al. Spatial synchrony of malaria outbreaks in a highland region of Ethiopia. Trop Med Int Health. 2012;17(10):1192-201.

10. Patz JA, Hulme M, Rosenzweig C, Mitchell TD, Goldberg RA, Githeko AK, et al. Climate change-regional warming and malaria resurgence. Nature. 2002;420(6916):627-8.

11. Teklehaimanot HD, Lipsitch M, Teklehaimanot A, Schwartz J. Weather-based prediction of Plasmodium falciparum malaria in epidemic-prone regions of Ethiopia I. Patterns of lagged weather effects reflect biological mechanisms. Malaria J. 2004;3:41.

12. Lindsay SW, Birley MH. Climate change and malaria transmission. Ann Trop Med Parasit. 1996:90(6):573-88

13. Beck-Johnson LM, Nelson WA, Paaijmans KP, Read AF, Thomas MB, Bjornstad ON. The effect of temperature on Anopheles mosquito population dynamics and the potential for malaria transmission. PLoS One. 2013;8(11), e79276.

14. Martens WJM, Niessen LW, Rotmans J, Jetten TH, Mcmichael AJ. Potential impact of global climate-change on malaria risk. Environ Health Persp. 1995;103(5):458-64.

15. Beier JC. Malaria parasite development in mosquitoes. Annu Rev Entomol. 1998:43:519-43.

16. Smith MW, Macklin MG, Thomas CJ. Hydrological and geomorphological controls of malaria transmission. Earth-Sci Rev. 2013:116:109-27.

17. Hardy AJ, Gamarra JGP, Cross DE, Macklin MG, Smith MW, Kihonda J, et al. Habitat hydrology and geomorphology control the distribution of malaria vector larvae in rural Africa. PLoS One. 2013;8(12), e81931.

18. Shaman J, Day JF. Reproductive phase locking of mosquito populations in response to rainfall frequency. PLoS One. 2007;2(3), e331.

19. Paaijmans KP, Wandago MO, Githeko AK, Takken W. Unexpected high losses of Anopheles gambiae larvae due to rainfall. PLoS One. 2007;2(11), e1146.

20. Midekisa A, Senay G, Henebry GM, Semuniguse P, Wimberly MC. Remote sensing-based time series models for malaria early warning in the highlands of Ethiopia. Malaria J. 2012:11:165.

21. Males S, Gaye O, Garcia A. Long-term asymptomatic carriage of Plasmodium falciparum protects from malaria attacks: a prospective study among Senegalese children. Clin Infect Dis. 2008;46(4):516-22.
22. Harris I, Sharrock WW, Bain LM, Gray KA, Bobogare A, Boaz L, et al. A large proportion of asymptomatic Plasmodium infections with low and submicroscopic parasite densities in the low transmission setting of Temotu Province, Solomon Islands: challenges for malaria diagnostics in an elimination setting. Malaria J. 2010;9:54.

23. Cucunuba ZM, Guerra AP, Rivera JA, Nicholls RS. Comparison of asymptomatic Plasmodium spp. infection in two malaria-endemic Colombian locations. Trans R Soc Trop Med Hyg. 2013;107(2):129-36.

24. Graves PM, Richards FO, Ngondi J, Emerson PM, Shargie EB, Endeshaw T, et al. Individual, household and environmental risk factors for malaria infection in Amhara, Oromia and SNNP regions of Ethiopia. Trans R Soc Trop Med Hyg. 2009:103(12):1211-20.

25. Jima D, Getachew A, Bilak H, Steketee RW, Emerson PM, Graves PM, et al. Malaria indicator survey 2007, Ethiopia: coverage and use of major malaria prevention and control interventions. Malaria J. 2010;9:58.

26. Negash K, Kebede A, Medhin A, Argaw D, Babaniyi O, Guintran JO, et al Malaria epidemics in the highlands of Ethiopia. East Afr Med J. 2005;82(4):186-92

27. Animut A, Balkew M, Lindtjorn B. Impact of housing condition on indoorbiting and indoor-resting Anopheles arabiensis density in a highland area, central Ethiopia. Malaria J. 2013:12:393.

28. Emerson PM, Ngondi J, Biru E, Graves PM, Ejigsemahu Y, Gebre T, et al. Integrating an NTD with one of "The Big Three": combined malaria and trachoma survey in Amhara region of Ethiopia. PLoS Neglect Trop D. 2008;2(3), e197.

29. Teklehaimanot HD, Schwartz J, Teklehaimanot A, Lipsitch M. Weather-based prediction of Plasmodium falciparum malaria in epidemic-prone regions of Ethiopia II. Weather-based prediction systems perform comparably to early detection systems in identifying times for interventions. Malaria J. 2004;3:44

30. Wimberly MC, Chuang T-W, Henebry GM, Liu Y, Midekisa A, Semuniguse P, et al. A computer system for forecasting malaria epidemic risk using remotelysensed environmental data. In: International Environmental Modelling and Software Society (iEMSs) Proceedings of the 6th International Congress on Environmental Modelling and Software; Leipzig, Germany. 2012.

31. Senay GB, Bohms S, Singh RK, Gowda PH, Velpuri NM, Alemu H, et al. Operational evapotranspiration mapping using remote sensing and weather datasets: a new parameterization for the SSEB approach. J Am Water Resour As. 2013:49(3):577-91.

32. Midekisa A, Senay GB, Wimberly MC. Multisensor earth observations to characterize wetlands and malaria epidemiology in Ethiopia. Water Resour Res. 2014:50(11):8791-806.

33. Jima D, Wondabeku M, Alemu A, Teferra A, Awel N, Deressa W, et al. Analysis of malaria surveillance data in Ethiopia: what can be learned from the Integrated Disease Surveillance and Response System? Malaria J. 2012;11:330.

34. Central Statistical Agency of Ethiopia. Population and housing census report 2007. Addis Ababa, Ethiopia. 2010.

35. Burnham KP, Anderson DR. Model selection and inference: a practical information-theoretic approach. New York: Springer; 2002.

36. R Development Core Team. R: a language and environment for statistical computing. Vienna, Austria. 2014.

37. Thomson MC, Mason SJ, Phindela T, Connor SJ. Use of rainfall and sea surface temperature monitoring for malaria early warning in Botswana. Am J Trop Med Hyg. 2005;73(1):214-21.

38. Thomson MC, Connor SJ. The development of malaria early warning systems for Africa. Trends Parasitol. 2001:17(9):438-45.

39. Abeku TA, Hay SI, Ochola S, Langi P, Beard B, de Vlas SJ, et al. Malaria epidemic early warning and detection in African highlands. Trends Parasitol. 2004;20(9):400-5.

40. Ceccato P, Ghebremeskel T, Jaiteh M, Graves PM, Levy M, Ghebreselassie S, et al. Malaria stratification, climate, and epidemic early warning in Eritrea. Am J Trop Med Hyg. 2007;77(6):61-8.

41. Olson SH, Gangnon R, Elguero E, Durieux L, Guegan JF, Foley JA, et al. Links between climate, malaria, and wetlands in the Amazon basin. Emerg Infect Dis. 2009:15(4):659-62.

42. Wimberly MC, Henebry GM, Liu Y, Senay B. EPIDEMIA-an EcoHealth informatics system for integrated forecasting of malaria epidemics. In: International Environmental Modelling and Software Society (iEMSs) Proceedings of the 7th International Congress on Environmental Modelling and Software; San Diego, CA, USA. 2014 